\title{
Scapegoat for fraud in Germany?
}

Sir - You have published articles alluding to scientific fraud in Germany (Nature 387, $750 \& 389,105 ; 1997)$. Because my name was mentioned prominently on each occasion, your readers should be aware of some additional facts.

Last year I was accused in private of having been involved in falsification of scientific data. I immediately wrote a full explanation, tantamount to a confession, and then offered to resign my position at the University of Lübeck. The resignation was accepted in June 1997. I do not believe that further victimization is appropriate.

Commissions of investigation have been established by academic authorities in Berlin, Ulm, Freiburg and Lübeck. In each case the commission sat in camera, sought information from me and others on an informal basis and encouraged no formal legal representation for the accused. The commissions issued selective press releases but the full findings have not been sent to me or been made public.

I am forced to the conclusion that each commission met with the intention of limiting damage to the German academic community rather than discovering the full extent of culpability. It was only too easy to attack the person who had confessed while ignoring the evidence of greater wrongdoing that would require more rigorous investigation.

The resignation from my academic position at the University of Lübeck constituted part of a legal agreement by which I was offered a severance payment equivalent to almost one year's salary. The contract was signed by a representative of the Ministry of Science, Research, Education and Culture of the state of Schleswig-Holstein. In the event, the state government has reneged on its side of the agreement, claiming that its signatory was not authorized to sign and that the agreement is therefore void. I, however, am expected to honour my part of the bargain.

In summary, I have very readily admitted to having been involved in falsification of scientific papers, an achievement of which I am not proud. I resent, however, the fact that, because I alone have admitted my mistakes at an early stage of the investigations, official bodies have found it expedient to imply that I was the major or conceivably the only culprit and that I was responsible for false data appearing in numerous papers, on some of which I was not even a co-author.

\section{Marion A. Brach}

c/- Walter F Kalthoff,

Pacellistr. 14,

D-80333 München,

Germany

\section{AIDS therapy in Brazil}

Sir - In your article "Better adherence vital in AIDS therapy” (Nature 390, 326; 1997) you stressed the importance of persuading HIV patients to follow the complex new drug treatments.

We agree, but our data show that other factors may also be of importance, as shown by experience in Brazil where, since 1996, the government has made combined therapy available to all Brazilians with AIDS.

The Ambulatorio da Providencia Outpatient Clinic and Support House in Rio de Janeiro, run by the Roman Catholic Church, has worked on HIV infection since 1985. During that time, there has been a constant increase of HIV infection among our patients. The clinical population profile encompasses the poor and the 'social outcasts' of the city: slum (favela) dwellers, street children, sex workers, transsexuals and beggars. Some 700 HIV-positive/AIDS patients are followed up by the clinic and most of them are homeless or living in favelas. Some 25 homeless AIDS patients can be housed at the Santo Antonio Support House.

In 1990 we started a prospective study comparing survival time between homeless and formerly homeless housed individuals with AIDS in Rio de Janeiro. HIV-1-positive homeless subjects, HIV-positive volunteers who previously lived on the streets and agreed to live at our support house, and a control group of people living with relatives and who came from the poorest section of Rio society were followed up to 1997.

Survival time was calculated from the date of AIDS diagnosis until the date of death. We divided the study into two phases. The first phase was from 1990 to 1995, when combined therapy was not available (we used monotherapy and/or double therapy) and the second from 1996 when triple therapy was made available by the government.

In the first phase, the mean survival of the homeless group (27 patients) was 8.2 months (range 1 to 33 ), in the formerly homeless group (26 patients) 17.8 months ( 1 to 48 ) and in the control group (59 patients) 18.3 months (2 to 60 ). The results from the log-rank test for pairs of survival curves revealed significant statistical differences between the groups of homeless and formerly homeless subjects $(P=$ 0.0018 ) and the groups of homeless and housed subjects $(P=0.0001)$. In contrast, there was no significant statistical difference between the survival curves for the groups of formerly homeless and housed subjects $(P=0.9704)$. Better nutrition and hygiene, more frequent medical and psychological care together with controlled medicine intake, occupational therapy, decrease in promiscuity, alcohol and drug abuse and the provision of religious support may explain the difference in survival time observed in this phase of the study.

The second phase of the study has shown no deaths since the beginning of triple therapy (mean 13 months) for the formerly homeless (10) and housed (12) patients; all the patients are clinically well, CD4 counts have increased and viral loads are not detectable or below 700 copies (indicating efficacy of therapy). In contrast, the survival time of homeless subjects has remained the same as that observed previously, because we do not give combined therapy if we cannot monitor adherence to treatment.

The use of combined therapy has increased the cost of each patient on therapy at the support house. A new problem has emerged because the number of clinically well patients discharged from the house has been very low, consequently increasing the list of HIV-positive homeless waiting to be taken into the support house.

These findings highlight the severe impact of the HIV-1 epidemic and its treatment in people from the poorest part of our society. The results of this study should be the reason for some cautious optimism by governments and encourage them to pursue measures to deal with longer life of patients and resocialization of social outcasts.

Luiz R. R. Castello-Branco

Ambulatorio da Providencia,

Rua Francisco Eugenio 348,

Sao Cristovao,

Rio de Janeiro 22.941-120,

and Depto de Imunologia - FIOCRUZ, Av. Brasil 4365,

Rio de Janeiro 21.045-900, Brazil

e-mail:branco@gene.dbbm.fiocruz.br

Maria I. Linhares-Carvalho

Ambulatorio da Providencia

e-mail:inez@pontocom.com.br

Antonio C. M. Ponce de Leon

Depto de Estatistica, UERJ,

$R$ Sao Francisco Xavier 524,

Rio de Janeiro, Brazil

e-mail:deleon@vmesa.uerj.br 


\section{Arguments in favour of the space station}

Sir - The Microgravity Advisory Committee (MAC) of the European Space Agency has read with interest your leading article and Briefing about the International Space Station (ISS) ${ }^{1}$.

The MAC appreciates your efforts to clarify aspects of the scientific research planned on board the ISS and the technical and 'political' motivation for such an important international programme, but both the article and Briefing seem to show a negative attitude towards the project.

In both the physical and life sciences, research on phenomena and processes at near-zero gravity levels cannot be done on Earth for sufficiently long periods.

Moreover, the necessity to repeat experiments at a pace consistent with that of the on-ground research - considered a basic requirement — can be assured only on board space stations.

The conclusion of your leading article that "the [scientific] community has placed its negative scientific judgements of ISS on the record" sounds unfair because it is not well supported by evidence: although it is true for some scientific societies, it does not represent the general opinion of the scientific community as a whole.

First, of the many personal opinions given by scientists interviewed by Nature, few positive comments seem to have found their way into print.

Second, in the ELGRA Report on microgravity research in Europe

(September 1995), a committee consisting of a Nobel prizewinner and leading scientists recognized that "low-gravity is a useful tool - in some cases a unique tool - for the study of a number of physical and physico-chemical phenomena which are important in science, engineering and technology.... If the space station becomes available, the scientific community will make the best possible use of it to perform experiments." But, when writing of a "broad consensus" about the expected weak impact of the research planned for the ISS, such a statement is valid only if objective methods are used to establish it.

The experiments are being, and will be, chosen on the basis of rigorous peer-review procedures clearly stated in each announcement of opportunity. The only criterion has been and will be scientific excellence, a point on which there does exist a broad international consensus. Cost is not among the points the peers are asked to evaluate, for good reason. As correctly stated, the costs of these experiments, after deducting the costs of the orbiting laboratory, are not basically different from the corresponding experiments performed on Earth.

Research on gravity-related phenomena in life and physical sciences has, in the past 20 years, given important results despite the scarcity of flight opportunities: these include advances in the understanding of the stability and dynamics of liquid interfaces (liquid columns, Marangoni motions), of transport phenomena (diffusion, Soret effects, crystal growth), of many physiological processes (the treatises on respiratory physiology must be considerably revised in the wake of many flight results) and in cell biology.

The possibility of gaining exciting insights from the 'continuous' use of an orbiting laboratory represents a real 'quantum jump' in scientific development and a potent magnet to attract young researchers and top-level scientists, as has already happened in the past few years.

The ISS represents one of the most demanding and challenging efforts made in the field of international scientific and technical cooperation. Whatever the other reasons for this programme, the situation is much the same as for any project of similar size: it has an impact on every aspect of science and technology precisely because of its size and the intensive and

multidisciplinary collaboration it requires.

No scientific endeavour can, from the start, predict what benefit it may eventually have: let great projects grow and answer the question posed by Benjamin Franklin: "Of what use is the baby you have in your arms, Madam?"

\section{Alberto Passerone}

(MAC Chairman)

ICFAM-CNR,

Via de Marini 6, I-16149 Genova, Italy

e-mail:passerone@icfam.ge.cnr.it

Sir - Your discussion of the International Space Station ${ }^{1}$ failed to draw attention to two of the most important arguments in favour of this ambitious project.

One is the development of new institutional arrangements needed for the management of complex international space projects. The quotation from John Logsdon (ref. 1, p. 734) that "in effect, an international space agency has been created for the station" may be overstating things at present, but there are strong reasons for believing that, if humanity is to have a significant future in space, a World Space Agency of some sort will be both necessary and desirable ${ }^{2}$. If experience with building and operating the ISS helps to develop the institutional foundations for a future world space programme, that alone will be one of its most important legacies.

The other main argument in favour of the ISS is the experience that it will provide in building large structures in space. As your discussion highlighted, many scientists have grave doubts about the suggested scientific applications of the ISS itself. But considerable, if long-term, scientific advantages are likely to follow from an ability to construct large structures in Earth orbit and beyond (for example, large space telescopes, lunar and planetary outposts and, eventually, interstellar space probes ${ }^{3,4}$ ).

These arguments make sense, of course, only if one accepts that a significant human presence in space is a desirable future goal. Many in the scientific community do not accept this assumption, and the editorial pages of Nature have reflected this widespread scepticism. However, accepting that many of the arguments for an ambitious human space programme are social and political (reviewed in ref. 2) rather than narrowly scientific, it seems clear that science would be a major beneficiary. In which alternative future would we be likely to learn the most about the Universe and our place within it? And if we aspire to follow the latter course, it is not too soon to start laying the foundations for the technical and institutional infrastructure that will be required.

\section{A. Crawford}

Department Physics \& Astronomy,

University College London,

Gower Street, London WC1E 6BT, UK

e-mail:iac@star.ucl.ac.uk

Sir - International Space Station "Worry no. 4" (manpower) is not a worry! I consider it a positive sign that "many researchers admit they worry that the station will not live up to its potential". This is a measure of their eagerness to use the station to conduct unique research in the microgravity environment. One of your worries is, however, misstated in your Briefing ${ }^{1}$.

It implies incorrectly that insufficient crew time is available for research once construction is complete. It is true, and understandable, that crew time for research is limited during construction. But, when assembly is complete, the available crew time for research jumps to 160 hours per week, equivalent to four full-time crew members. Our best analyses show that this amount is not the constraining resource for the planned research.

The preservation and improvement of the research capability of the space station is a high priority of this programme.

\section{John-David F. Bartoe}

(Research Manager,

International Space Station)

NASA Johnson Space Center,

Houston, Texas 77058, USA

e-mail:john-david.f.bartoe1@jsc.nasa.gov 